\title{
Ectodermal dysplasia, trichoodontoonychial type
}

INSERM

\section{Source}

INSERM. (1999). Orphanet: an online rare disease and orphan drug data base.

Ectodermal dysplasia, trichoodontoonychial type. ORPHA:1818

Ectodermal dysplasia, trichoodontoonychial type is a form of ectodermal dysplasia with hair, teeth and nail involvement characterized predominantly by hypodontia, hypotrichosis, delayed hair growth and brittle nails. Additionally, focal dermal hypoplasia, irregular hyperpigmentation, hypoplastic or absent nipples, amastia, hearing impairment, congenital hip dislocation and asthma have been associated. There have been no further descriptions in the literature since 1996. 